In: Carsten Gansel, Dirk Vanderbeke (Hg.): Telling Stories.

Literature and Evolution (Spectrum Literaturwissenschaft 26). Berlin, New York: de Gruyter 2012, 30-49.

\title{
Is Storytelling a Biological Adaptation? \\ Preliminary Thoughts on How to Pose That Question
}

\author{
Katja Mellmann
}

Verbal storytelling - in a sense broad enough to include all forms from casual conversation across oral folklore to written literature - seems to be a universal human activity and has thus been considered an evolutionary adaptation several times in the past few years. The fact that a particular trait is a specieswide universal, however, does not automatically make it an adaptation; it could also be a contingent universal, that is, a cultural behavior which notably relies on biological substrates and therefore emerges in similar fashions in all human cultures, times, and milieus. Yet verbal storytelling is not only universal but also distinct to our species. The uniqueness of a trait can indeed be indicative of a biological adaptation ${ }^{1}$ in that we have reason to assume that this trait emerged newly in the given animal lineage and thus might owe its existence to the process of natural selection. However, since verbal storytelling completely depends on language, that is, another uniquely human faculty, ${ }^{2}$ the uniqueness of storytelling is hardly surprising and cannot serve as a conclusive argument for considering storytelling itself to be a specifically selected trait. Storytelling could simply be a particular use of language (though we shall see below that the relationship between language and narration is a little more complicated). A third possible indication of a biological adaptation, however, is the fact that storytelling seems to be a notably self-rewarding activity. It occurs on a much larger scale than would seem justified by rational choice or other reasons. As fitness-enhancing behaviors should, as a rule, be intrinsically motivated under certain conditions, the unusually high frequency of

1 Note that this is not to say that, conversely, a trait has to be distinct to a species in order to be an adaptation. There are many adaptations which we have in common with other species (socalled "homologues," which derive from common ancestors, and "analogues," which result from comparable selection pressures).

2 Though much more of the capabilities involved in producing and understanding language than previously thought can also be found in other animals (cf. Hauser and Fitch 2003), there are strong reasons to assume that human language in its present form, i.e., as an incomparably sophisticated design for "grammar," is a distinct adaptation of the human species (cf. Pinker 2003); see also Donald 1991, pp. 236-261. 
storytelling might indeed be revealing of an innate preference for this behavior.

The hypotheses put forward in this chapter will build mainly on that last-mentioned aspect. I shall ask: What are these conditions under which people "instinctively" - that is, spontaneously, effortlessly and pleasurably begin to tell stories, and about what? To what suppositions about the original adaptive function of storytelling do these situational conditions and the pertinent stories' properties guide us? Hence I do contemplate the possibility that storytelling is an evolutionary adaptation of the human mind, although I will not be able to conclude this chapter with a definite Yes or No response to the question stated in my title. I do not think this question is unanswerable, but I believe that a lot of empirical testing will have to be done before trying a sustainable answer. Yet before answering a question it is good to carefully think about how to pose it in the first place. Thus, even if the following considerations cannot be more than preliminaries to future research, I regard them as indispensable, because fruitful empirical tests prerequire a detailed theory from which we can derive risky hypotheses.

Most of the existing proposals for viewing human storytelling as a biologically adaptive trait do not provide such a detailed, and thus testable, theory. The most frequent kind of statements in this vein consist in the observation that storytelling is a human universal plus the more or less straightforwardly connected search for its adaptive function. However, as I said above, the fact that a trait is universal does not guarantee that it also is an adaptation in the biological sense of the term, and asking immediately what function it has been selected for might be precipitate. Accordingly, propositions for the adaptive value of storytelling are numerous and sometimes resemble "just so" stories ${ }^{3}$ rather than adaptationist analyses. They often deal with very extensive notions of "narrative" and suggest, for example, that narrative fosters social cohesion, enables (collective and individual) identity, enhances emotional intelligence, facilitates creativity and thinking beyond the here-and-now, or absorbs and assimilates the complexity of the world. These may all be important effects of storytelling, ${ }^{4}$ but they are not

3 The title of Kipling's deliberately fanciful etiological tales about the origins of animal characteristics is a commonly used expression in criticizing evolutionary explanations which do not meet the criteria of testable hypotheses.

4 I emphasize "may," because evidence that the engagement with stories really has such effects sometimes indeed seems hard to get. With respect to emotional intelligence (EI), for example, the (non-significant) negative (!) correlation of EI with studying literature (and, remarkably, a significant positive correlation of EI with an education in the natural sciences) found by Eirini Tsiknaki (2005) should at least make us cautious; all the more as the study clearly set out to affirm a positive correlation between reading and EI. The usual reference for positive evidence is Keith Oatley and colleagues (e.g., Mar et al. 2006; Mar et al. 2009), but their studies are, as far as I can tell, best interpreted as studies on the role of stories in ontogenetic development. It is not surprising that empathic skills develop better in a child if it is served with adequate 
suitable as evolutionary explanations on the ultimate level. First, because asking what something might be "good for" is not automatically identical with determining the crucial advantage in gene reproduction. Second, because the adaptive values of the mentioned kinds are not cogently related to any particular behavior of storytelling but could be ascribed to a multitude of cultural activities, if not to culture itself. As propositions of this kind mostly occur as casual, sometimes merely parenthetical, remarks and rarely in the form of detailed demonstrations - and as they are uncountable in number -, I will not discuss them individually here but confine myself to propositions substantial enough to require serious discussion.

A second, more elaborate type of pro-adaptation statement postpones the question of the ultimate cause for a while and first focuses on the proximate mechanism. Those approaches ask if we have reasons to assume a "special design" behind the universal human activity of storytelling. One way to approach this question is to investigate narrative form, or "narrativity," in order to decide whether those forms of speech called "narrative" are both consistent and specific enough to assume a "hard-wired" cognitive program that produces them. While I think that this is a very good idea in principle, this method has not yet lead to convincing results, as I shall outline in the first section of this chapter. If we take away from narrative structure everything that can be explained as a byproduct of other cognitive faculties, very little (if anything) remains that would require additional explanation. Another way of searching for a "special design" behind storytelling, though, would be to look not at the objectified product of the assumed mechanism but at the producing mechanism itself, that is, to investigate the specificity of the behavior of storytelling and its circumstances. This is why, in the second section, I will focus on narration as behavior rather than a particular form or structure. If I am right in assuming that there is something like an "instinctive" behavior of storytelling that reveals itself in an improbably high ratio of occurrence (and this, so far, is largely speculation), ${ }^{5}$ then we would indeed have something in need of explanation. However, even then, as we shall see, this behavior seems to comprise a plurality of specific cognitive mechanisms rather than being one distinct cogni-

stimuli during the appropriate sensitive period, and that a deprivation of such stimuli entails a poorer development. But the question in the above-mentioned line of argument is not whether stories are suitable stimuli for a specific developmental demand but whether the engagement with stories generally (that is, also and foremost in mature organisms) enhances our social and emotional intelligence (and if so, whether this is a selectionally relevant advantage). For a comprehensive and critical survey of research on the question of whether reading enhances empathic skills, and whether this entails a raised preparedness for prosocial behavior, see Keen 2007.

5 For a survey of first research in this respect see Foster 2004, pp. 78-99; also Dunbar et al. 1997, esp. pp. 232f., and Barrett et al. 2001, pp. 334-336. Analyses of media content (like those by Schwender 2006) are also informative in this regard. 
tive program per se. I shall conclude with the supposition that verbal storytelling is probably the convergent effect of an entire suite of adaptations to different selection pressures. In this perspective, Michelle Scalise Sugiyama's proposition that narrative originally evolved as a means to store and transmit adaptive information ${ }^{6}$ will be assessed as a still valid but generalized formulation which requires differentiation into "hard-wired" biological adaptations on the one hand and early cultural uses of language and narration on the other. Drawing on Robin Dunbar's theory of language evolution, I also try to sketch a chronology for the evolutionary emergence of the narration instincts hypothesized in this chapter, considering the exchange of social knowledge to be the first among them (and thus supporting the frequently expressed hunch that storytelling performs an eminently social function; cf. Carrithers 1991; Scalise Sugiyama 1996; Dautenhahn 2003; László 2003; Oatley and Mar 2005; Flesch 2007; Hoeg 2009).

\section{Looking for the explanandum}

To assume a biological adaptation means to assume a functional physiological or psychological design. It can be described as a "hard-wired" combination of submechanisms that was selected over other variants and now reliably develops in every healthy member of a species. If storytelling is not merely the effect of several biological substrates that combine similarly in every storytelling act, but the reliable product of a special cognitive design, then all stories across times, places, and individuals, should look pretty much the same.

On the one hand, this seems to be indeed the case if we look at the numerous "narrative universals" that have been suggested, for instance, through Vladimir Propp's fairytale analyses and also some more recent studies on plot "archetypes" (cf. Booker 2004; Bischof 1998), emotional story prototypes (cf. Hogan 2003), or "epic triads" as innate plots (cf. Eibl 2008). Moreover, we all roughly know what we mean by "narrative" and have a commonsensical idea of what a narrative looks like. Even if a completely undisputed definition of "narrative" or "story" that would be affirmed by all literary scholars does not exist, there are plenty of good propositions for such a definition, or a list of minimal criteria, which at least find pragmatic acceptance in a given context.

On the other hand, even if we avoid the more contentious issues raised by attempts to define stories (as, for instance, whether the represented events have to be past events in relation to the time of representation; or whether non-verbal modes of representation, like in films, can still be called "narrations"), this thing called "narrative" does not look as homogenous as

6 See Scalise Sugiyama 2001a; Scalise Sugiyama 2005, for the overarching hypothesis. The project as a whole comprises a series of studies on oral folklore, published since 2001. 
our gestalt notion of it suggests. Narratives may employ the first person as well as the third (or even the second), they may present events in the ordo naturalis or in an ordo artificialis, and the narrator may be part of the one and only storyworld or (as a "heterodiegetic narrator") give rise to another (meta-)storyworld incongruent with the external world of the storyteller. Furthermore, even if the narrated events are located in a relative past, the narration may equally employ the present tense and thus shade into more dramatic "mimesis" (as opposed to diegesis). Similarly, there are uncountable gradations between "focalized" and "unfocalized" narrations (cf. Mellmann 2010a, p. 124), between "showing" and "telling" modes, scenic and reporting, or even reflexive, styles of narration. These manifold expressions of "narrative" should raise skepticism against a "hard-wired" cognitive program behind these phenomena. On the contrary, if narrative is taken to be the unstable cultural product of exploiting many diverse cognitive capacities, such a plurality of narrative forms is exactly what we would expect.

On the other hand again, the fact that we still understand all of these formal and functional possibilities as encompassed by the notion of "narrative" could be used as evidence that there is in fact some common ground or basic substrate here. But there we are back at the initial problem: Is this perceived common ground a cultural conception that emerges similarly in all cultures simply because of the biological substrates involved in narration, or is it a symptom of "hard-wired" special design? My supposition is that the mere capacity for storytelling is sufficiently explained by preexisting cognitive abilities which have not specifically evolved for storytelling, but that our intuitive notion of "story" may indeed be revealing of a number of biological constraints operating on the first storytelling practices in an evolutionary past which have shaped the biological proto-type of narration that still influences our intuitive concept of "story."

As John Tooby and Leda Cosmides have convincingly argued, there is no immediate need to explain something about narrative structure, because

we evolved not so long ago from organisms whose sole source of (non-innate) information was the individual's own experience. Therefore, even now our richest systems for information extraction and learning are designed to operate on our own experience. It seems therefore inevitable, now that we can receive information through communication from others, that we should still process it more deeply when we receive it in a form that resembles individual experience, even though there is no extrinsic reason why communicated information needs to be formatted in such a way. That is, we extract more information from inputs structured in such a form. [...] People prefer to receive information in the form of stories. Textbooks, which are full of true information, but which typically lack a narrative structure, are almost never read for pleasure. We prefer accounts to have one or more persons from whose perspective we can vicariously experience the unfolding receipt of information, expressed in terms of temporally sequenced events (as experience actually comes to us), with an agent's actions causing and caused by events (as we experience ourselves), in pursuit 
of intelligible purposes. [...] stories are told in a way that mimics the format in which experienced events are mentally represented and stored in memory, in order to make them acceptable to the machinery the mind uses to extract meaning from experience. (Tooby and Cosmides 2001, p. 24)

From this perspective, the frequently described "narrativity" of our experience, memory, consciousness, ${ }^{7}$ and reasoning ${ }^{8}$ would sufficiently account for the narrative "format." The way our brain (and that of other species capable of self-propelled movement) processes information simply shapes our mental representations and thus from the very outset also shapes every external representation system with which these mental representations are socially communicated. That is, the experiential format of our mental life already determined the very first manifestations of human language, thus shaping language and many of its properties itself. Thus, rather than speaking of "narrative thinking," "narrative construction of experience," a "narrative structure of empathy," and the like, perhaps we should call narrative "mindlike speaking." Conversely, language can be said to show kind of a natural tendency to issue into experiential ("narrative") formats (cf. Donald 1991, p. 257), because it is based on the way we think, which in turn derives from the way selfpropelled organisms gather and process environmental information. So, is there something that remains, something we regard as crucial for our notion of storytelling but which is not already covered by this natural tendency to experiential formats in verbal representation?

I have for some time been thinking about the third-person narration as something not immediately self-evident. The fact that we are able to recount not only our own experiences but also those of another person (real or fictitious) to me seems something worth noting at least. Indeed, the classical "story" in the sense of our (my?) gestalt notion of it would rather be "Once upon a time there was ...," that is, a heterodiegetic third-person tale, than the homo- or even autodiegetic communication of someone's own experience. But "third persons" are of course part and parcel of our regular ancestral environment, and if we can see others do something we should also be able to tell what we see. In other words, the grammatical option of "third person" is not less innately biased than, for instance, the option of a past tense resulting from our capacity to remember things. Yet still there is something remarkable about it: primates, and especially humans, are particularly attentive to others' actions. The more complex the social structure in a species, the more important it is to observe and remember also other group members' conduct and experiences (cf. Dautenhahn 2003) and to build complex mental representations of "society" (its hierarchical structure

\footnotetext{
7 Cf. the description of consciousness as a continuous "wordless storytelling" by Antonio R. Damasio (1999).

8 Cf., for instance, Lloyd 1989, pp. 225-228, 233 f.
} 
and causal dynamics, personal interrelations, distribution of knowledge and resources, etc.) in order to be able to act within these complex social settings (cf. Carrithers 1991; Barrett et al. 2001, p. 334; Hoeg 2009). Storytelling indeed seems to be quite essentially about third parties. Not only: "Let me tell you what happened to me yesterday," but also: "Let me tell you what a third party and I did yesterday," or even: "Let me tell you what I witnessed a third party doing;" now let's drop the source tag "I witnessed," and there we are with a classical third-person narrative. So even if the mere capability to think (and talk) using a "third person" concept is nothing that our storytelling species would have had to invent newly, it might be something at least of raised significance to our species, and thus hint at an important (perhaps even biologically anchored) motivation for telling stories.

Others have pointed out that something unusual - some breach (cf. Bruner 1991/92, pp. 11-13; Herman 2002, pp. 91f.) or conflict (cf. Scalise Sugiyama 2005, pp. 185f.) - is what really makes a story a story. We call "story" not so much the meandering rendition of interchangeable happenings but rather the selective and incisive account of a "non-contingent" (Eibl 2004, p. 255) sequence of events worth our interest. However, the Aristotelian beginning-middle-ending structure, Yuri Lotman's "sujet," the archaic narrative models of quest, virtue's triumph, and reunion of the lovers, Propp's narrative "functions," and so on, all rest on gestalt schemata which, as Karl Eibl has plausibly suggested, are not unique to storytelling but can be explained as preexisting mental schemata that evolved to guide the behavior of our ancestors (including nonhumans) in an adaptive manner (cf. Eibl 2008; Eibl 2004, pp. 267f.). So this is another characteristic of stories which seems sufficiently explained as a byproduct of other cognitive traits. But again I would say that our intuition of a story necessarily involving something unusual, or "bad gestalts" that require resolution, can inform us about important motives (or even innate triggers) for storytelling.

Brian Boyd has proposed fiction as something that needs further explanation (cf. Boyd 2009, pp. 15, 186-208). The fact that we tell not only true but also (and perhaps even on a larger scale) purely invented stories is indeed something remarkable. And many other scholars have pointed out that it often is in the form of stories that humans think about the non-actual, design alternative worlds, make graspable the ungraspable, link actual experience with more general rules and principles, and so on. The problem is, however, that counter-factual (and hypothetical, etiological, parabolic, case-based, etc. ${ }^{10}$ ) thinking, too, is nothing unique to storytelling, but seems

9 Productively picked up recently by Kafalenos 2006.

10 Fiction can indeed be many different things. For the general problem of taking abstract concepts as a starting point for adaptationist analyses in Boyd's study see my review (Mellmann 2010b). 
to rise (as one among many other forms) from a more general capacity to think in "decoupled" modes (cf. Cosmides and Tooby 2000; Tooby and Cosmides 2001, pp. 19-22). But even if fiction is not, as Boyd proposed, a distinct adaptation, the observation that fictional storytelling is something of great relevance to our species might indicate that, if storytelling is in fact an adaptation, its biological function should not exclusively depend on historically true information.

Scalise Sugiyama has particularly emphasized the stunningly high resolution of information rendered in a verbal mode in comparison to other modes of representation (cf. Scalise Sugiyama 2005, pp. 181-183; see also Pinker 2003). Surely this is true for any highly conventionalized ("arbitrary") semiotic system, regardless of its particular medium (gestures, vocal sounds, pictograms), but in the case of humans it indeed was vocal language that in the long run established itself as the predominant and most efficient mode of communication. ${ }^{11}$ Thus, even if we already had non-verbal, directly "mimetic" ways of representing events in a storytelling-like manner before language, as H. Porter Abbott (2000) with reference to Donald (1991, pp. 162-200) has persuasively suggested, the acquisition of language might have been an important step in the emergence of human storytelling.

As we have seen, narration might have merely been the linguistic expression of a great number of preexistent perceptive and cognitive mechanisms, some of them dating back far to our nonhuman ancestors. However, the idea that first there was a particular way of thinking, then we developed language (for whatever reason), and then we began to tell stories, would surely be inadequate. Language of course was not invented in one day but slowly elaborated in hundreds of thousands of minuscule steps of using vocal sounds for this or that particular purpose, that is, in countless steps of ritualization, grammaticalization, ${ }^{12}$ and developing an increasing level of arbitrariness which, by its "reifying" (cf. Eibl 2004, pp. 213-275) impact, in turn influenced the way we were thinking (cf. Eibl 2004; 2010). ${ }^{13}$ Also, to say that narration is only a particular use of language would be too easy, because by building on experience-related cognitive programs language probably showed kind of a "(proto-)narrative" quality from the very outset. Furthermore, like any other trait that has been genetically stabilized so that it now reliably develops in a species, our various cognitive and linguistic skills, too, when they develop in a human child, do so with the help of spe-

11 For a telling reconstruction of the emergence of human language (discussing also the hypothesis of sign language as a first and already very efficient form) see Eibl 2010.

12 For instance, the "syntax threshold" (cf. Pinker 2003, p. 32) hints at an external selection pressure (namely, an increased combinatorial structure of the environment) and thus also shows that thinking, language, and external needs to exchange particular kinds of information, are mutually dependent rather than evolving one after the other.

13 Cf. also Donald's "third transition" (Donald 1991, pp. 269-360). 
cific developmental mechanisms (cf. Tooby and Cosmides 2001, pp. 14f.) that is, with the help of "play." I want to particularly stress that, because this is where the "art" of storytelling comes in.

Verbal "art" (including "fiction", but not only that) emerges continuously as a byproduct of specialized developmental mechanisms which drive us to execute our immature cognitive programs in a playful "organizational mode" (Tooby and Cosmides 2001, p. 16). Just like the little infant, exploring its organ of speech, produces a kind of "concrete poetry," so the toddler, developing its capacity to represent others' intentions and beliefs, tries out the boldest lies on its mates and caregivers; or, when developing a sense of probability, logical consistency etc., tries out the boldest inversions of these concepts; or, when developing specific innate mechanisms of fear (and other emotions), makes up the boldest stories of horror and catastrophes; and so on and so on. ${ }^{14}$ Adults not only interact with their children and thus often join in that playful nonsense, they also "play" for themselves or with other adults. Humans on a much larger scale than any other animal species capable of play keep on playing even after maturation. Executing our skills for linguistic representation in the organizational mode, feeding our emotional system, challenging our cognitive "scope syntax" (a mental tagging system for different sorts of applicability of information; cf. Cosmides and Tooby 2000; Tooby and Cosmides 2001, pp. 19-22), calibrating our perceptual apparatus with "super-normal" sounds, training and enhancing mental scripts, etc. - this all entails the continuous possibility of stories which are not plain reports of historically true events, but rather narratives exaggerated in some details; epic amplifications or abbreviations to the "gist" of it (e.g., stylized to convey a certain "moral of the story"); narratives embellished with puns, rhymes, structures of repetition; intensified by certain focalization strategies; of a higher or lower degree of causality than actual events normally show; and so on.

So even in the most elaborated kinds of artful ("literary") storytelling there is nothing that clearly exceeds the already present cognitive capacities (including their developmental mechanisms) and would thus require special explanation. Yet I have outlined a couple of features in storytelling that seem to be important somehow, and are perhaps informative for the question of special design. Our interest in others, our preference for the "unusual," our unabated appetite even for inaccurate information, and the sophistication of event representation through language all point to pragmatic factors of storytelling - motivation, applicability, efficiency - which might be revealing of how we came to show such a peculiar behavior in the first

14 I think Boyd (Boyd 2009, pp. 177-187) makes too much of these qualities of children's storytelling by taking them as a paradigm of specific "functions" of art and fiction (like rousing attention, or exploring the possible around the real). 
place. If there is something like a narration "instinct," these factors should play a functional role in it (and have thus produced the intuitive notion, or semantic proto-type, of "story" which I took as guidance here). So let us now turn to the question in what situations people most obviously show such a presumed narration instinct.

\section{Narration Instinct(s)?}

The overwhelming extent to which people in Western societies talk about themselves, their lives, beliefs, hopes, and experiences could tempt us to assume a very general basic instinct of talking about oneself, constantly producing autobiographical narratives. However, as historians we know that the extensive souci de soi of individuals in modern Western societies is a very recent development and people in former times seem rather dull, in comparison, in this regard. Also, from the standpoint of evolutionary psychology we would rather expect a highly domain-specific than domain-general mechanism (or even several differently domain-specific mechanisms), that is, not a discretionary "talking of oneself" but talking of specific events in specific kinds of situations. Volker Heeschen, for example, has described a strongly situationspecific kind of narration in Papuan societies:

I heard an Eipo woman refer to her own exhaustion by alluding to smoke rising from a nearby mountain and speculating that it came from a fire kindled by a long-suffering woman from the Fa valley exhausted from her daily tasks. (Heeschen 2001a, p. 187$)^{15}$

Heeschen sees at work here a general principle of speech in small societies which he calls indirection. Directly to address another person or revealing one's own interests would seem offensive and indecent in those societies, and this is why many speech acts are transformed into songs and fairy tales in which the true circumstances are veiled as fictitious events and characters. I think this is a very deliberate use of narration which involves complex cognitive operations on a level way above instinctive behavior. Heeschen, too, emphasizes the cultural specificity and aesthetic sophistication of that manner of speaking and pins down as an obviously "instinctive" behavior only our urge to break silence (cf. Heeschen 2001a, pp. 180, 190f.) ${ }^{16}$ in an encounter. And this indeed is something we should keep in mind when searching for more

15 Full quotation of the woman's utterance in Heeschen 2001b, pp. $145 f$.

16 This "phatic" function of language, in Roman Jacobson's terms, corresponds nicely with Robin Dunbar's idea about the beginning of language in using vocal sounds as an extension of grooming in primates (cf. Barrett et al. 2001, pp. 322-334), but Heeschen (2001a, pp. 185f.) emphasizes that the content of utterances is not completely irrelevant in this function. The instinct to break silence, according to Heeschen, is automatically a "narration instinct" in that it inclines us to "map the world" (pp. 181f.) and, by ritualization and play, also to tell stories and transpose reality into fiction (cf. Heeschen 2001b, pp. 161f.). 
fundamentally biological instances of narration. Is there something beneath such culturally learned ways of telling stories with quite conscious purposes? What is it that we more or less thoughtlessly talk about if we simply want to break silence with a conversational partner?

Suppose that the silence is there for some reason and two people in a given situation do not have a lot to talk about; the cliché says that they will start talking about the weather. Clichés can sometimes be heuristically useful lenses into the evolutionary past. The weather conditions - and indeed not only the immediately present, but also bygone ones (which have had impact on our present condition and influence our future-directed cognition and behavior) - are a highly relevant kind of information in ancestral environments. To share the observations one has made, as well as one's reflections on it, with another might be a good way of preparing collective actions ${ }^{17}$ (like building a shelter) which could not be accomplished by a single individual alone.

Another heuristic lens on innate mechanisms is irrational behavior. Suppose you are on a holiday in a foreign country and meet a compatriot with whom you are talking for a while, and the moment you mention your hometown (a city of, say, 200,000 people) he asks if you "by any chance" know $\mathrm{Mr}$ So-and-so. And maybe it is not even of great relevance to him whether you know that person, but he "just simply thought that he would ask." And suppose further, you do not know that Mr So-and-so but another person of the same name from a different city, and you tell your compatriot a funny story about this person and he listens to you quite readily. Things like that occur, and I think this could be indicative of an instinctive disposition to talk (proto-narrate) about social relations and what they entail. According to Dunbar and colleagues, around two thirds of our relaxed conversation time is indeed devoted to social topics and, of this time, one third to information about third parties (cf. Dunbar et al. 1997). ${ }^{18}$ Those numbers are of course very provisional as long as we do not have extensive cross-cultural ${ }^{19}$ studies and, moreover, situation-specific studies that determine the situational circumstances that cause us to gossip about certain topics and avoid others. More fine-grained categories of topics will then have to be developed in order to decide what specific selection pressures (e.g., the so-called free rider problem; cf. Dunbar 2004, pp. 106-108; Scalise Sugiyama 2008) ${ }^{20}$ might

17 Cf. Carrithers 1991, p. 313, on "making society."

18 See also Mesoudi et al. 2006, showing that social gossip material (defined as intensely involving third-party information) is recalled to a larger extent and more accurately than non-social gossip materials.

19 Studies on conversation topics among Zinacantan Indians in southern Mexico show similar results (cf. Dunbar et al. 1997, pp. 241f.).

20 See also, explicitly from a nonadaptionist / byproduct standpoint, Flesch 2007. Interestingly, Dunbar found that "only about 3-4\% of conversation time centers around 'malicious' (or 
have shaped these assumed "gossip instincts." And, as to the literary question of storytelling, we also require more fine-grained categories of form in order to examine to what extent in gossip we really use more strictly narrative formats and to what extent maybe even more stylized, story-like forms of narration. ${ }^{21}$ And we would need to investigate the extent to which those stories perhaps exceed the circle of really existing social networks and migrate into more general or even explicitly fictional social settings.

Another innately biased incentive for narration might be the finding of food resources (at least if they are rich enough to feed more than only the discoverers). We know analogue phenomena from the animal kingdom: chickens, for instance, emit characteristic "food calls" upon discovering an edible object in order to inform their conspecifics (cf. Evans and Evans 1999); monkeys show a quite elaborate, socially strategic food call behavior (cf. Chapman and Lefebvre 1990); and if the waggle dance in bees is what we take it to be (this seems to be controversial at the moment), then there even is an analogue of specifically "narrative" food calls. Interestingly, Walter Burkert explains the literary theme of quest / adventurous journey as basically the verbalization of a biological program for foraging activities in humans and other animals (cf. Burkert 1998, pp. 81-85; see also Scalise Sugiyama 2001b; Scalise Sugiyama and Sugiyama 2009). If we furthermore posit a special psychic mechanism that prompts us to communicate our foraging experience upon homecoming, that is, to produce narrations of a certain kind, then those kinds of narratives would be among the many protoforms of literature, and Burkert's derivation would prove valid even above the "byproduct" level. The original instinct for food calls might be largely masked in industrialized societies, in which food is abundantly available. But think of "good bargain" stories people tell one another after their weekend shopping tours, and the like.

Another type of experience which is almost inevitably told about might be dangerous situations. Suppose you have nearly had a car accident or there was an attempted break-in at your place. It is unlikely that you will not tell your friends and colleagues about it the next day, even if you are all right after all and nothing has happened to you or your belongings. Of course, this should be sufficiently explained by a certain shock and excitement

negative) gossip in the colloquial sense" (Dunbar et al. 1997, p. 242; see also Barrett et al. 2001, pp. 336-338) and that negative gossip is not transmitted significantly more extensively or accurately than other social topics (cf. Mesoudi et al. 2006). Perhaps negative gossip is a matter rather of impersonalized (hypothetical, invented, etc.) stories - for example, of the "Well, this is how it goes ..." kind as found in many fairy tales - than of real accounts. And perhaps this is due to the need for indirection in certain circumstances which Heeschen (2001a; 2001b) has observed.

21 Further investigations in this regard might benefit from linguistic descriptive models of narrativity as developed by and since William Labov and Joshua Waletzky; cf. the stock-taking volume by Michael G. W. Bamberg (1997). 
which is reason enough to tell about the unsettling experience. In light of Scalise Sugiyama's findings about the depiction of natural predators in oral folklore (cf. Scalise Sugiyama 2004; Scalise Sugiyama 2006), however, I believe that there is more to it than just stress-induced talkativeness. Take as an example the ritualized "How are you?" in the English-speaking world (and equivalents in many other languages), or the vast extent to which we exchange stories of illness, frequently about third parties which are not, or only remotely, known to the interlocutor. It might well be a fitness-enhancing strategy to make everybody around aware of possible dangers and their specific properties, even independently of the actual presence of these dangers. Moreover, if we take into account the fact that, in ancestral environments, it is of immediate significance to survival (and thus genetic reproduction) that already the little child quickly learns to recognize and efficiently avoid predators and other dangers, it seems likely that the instinct to tell stories about dangerous situations is originally rooted in our behavior towards children. Curiously, we enjoy telling "scary stories" to little children much like we enjoy rough-and-tumble play with them, making them dizzy, or just saying "Bouh!" Similarly, ghost stories at the bonfire and a midnight hike are must-dos at every children's summer camp. Why? Given that we normally do not mean to torture our children, there must be another - unconscious, but all the more effective - reason why we do such peculiar things.

In view of prevailing motifs in oral folklore, we surely have to add another important topic to our list: namely, etiological explanations like those typically present in many mythological tales. I think etiological myths, too, could be the remote cultural product of a specifically evolved behavioral inclination to produce narratives. Suppose I notice my colleague having a surprised look at a new object on my desk. I will spontaneously start to recount to him the little story of how I found it yesterday and why I kept it and brought it here, etc. The explanation of the "unknown" might be a particularly productive incentive of storytelling - especially in the sense of fiction, because we can hardly tell "historically true" stories about what we do not know; and in the sense of stories about the "unusual," because the "usual" is what we already know. To not only form one's own silent stories about novel and strange facts (which would not exceed our general capacities for causal reasoning, "teleological" reflection on utility, and the like) but also to share one's own theories with others enhances our general knowledge about the actual environment and thus prepares the ground for what Michael Tomasello (1999) has called the "ratchet effect" of human culture. My supposition is that we are continuously producing stocks of (presently perhaps fairly irrelevant) information by exchanging kinds of information that seem worth preserving only for the reason that they are not available other than by social communication (i.e., information about something basically "un- 
known") and would hence be lost once we stop exchanging it. This behavior indeed seems adaptive in that it provides kinds of information which are especially well-suited to cooperate with specifically human forms of intelligence and behavior (cf. Tooby and DeVore 1987). If we share, for example, our experiences with new sorts of fruit, natural materials, topological formations, the changing of the seasons, and so on, we accumulate practical knowledge about those things and thus enhance our behavioral flexibility in new situations. As Jerry Hoeg with reference to Roy Rappaport has pointed out, it is not necessary that those cultural narratives rest on "scientifically true" explanations, as long as they allow for a coexistence of the culture with its environment (cf. Hoeg 2009, pp. 3-7). In that way, the story that one of my ancestors has lost his weapon in the mountains and this is why the mountain provides me with especially appropriate stones for arrowheads $^{22}$ is not worse than a scientific mineralogical analysis. And - seen from the "engineering" standpoint of evolution - what would be a better guarantee of such coexistence than forming our theories on the basis of stories about antecedent experiences, and on the basis of continuously socially comparing $^{23}$ them?

The resulting capacity for understanding the given in relation to a wider, or even "metaphysical" context is what is often emphatically understood as something uniquely human. I would not preclude, however, that many other animals, too, have their explanatory little mental stories. To socially share them in an extended and ritualized manner and, with language, even to build a quite persistent legacy of those stories (how the earth was made, how we came into it, why it is that we must give birth in pain, etc.) is what is indeed characteristic of humans, but I doubt whether we have reasons to call the whole thing a biological adaptation. Note that what I propose as a distinct adaptation of the human species here is merely the basic instinct to "break out into words (proto-narratives)" as soon as we believe to know more about something strange than a given interlocutor.

And this is something I want to emphasize for all the "narration instincts" I have hypothesized here. They all obviously rest upon preexisting mental adaptations, some of which might anchor deeply in our non-human past (like surely in the case of food calls). The mere fact that these adaptations are still influencing the stories we tell today (or might have told when we were hunters and gatherers) proves nothing. This could be explained as simply a byproduct of those adaptations in combination with our language faculty. What I have tried to suggest instead is the existence of a middle

22 For a real example see, e.g., Heeschen 2001b, pp. 158-160, on a Papuan girl's fairy tale about new objects brought by white people.

23 Cf. Bruner 1991/92 on "narrative discourse [...] as a viable instrument for cultural negotiation. You tell your version, I tell mine [...]" (p. 17) and on "narrative accrual" (pp. 18-20). 
layer of adaptations between those preexistent cognitive mechanisms and their verbal expressions: a layer of adaptations that specifically incline us to produce verbal communications on some specific kinds of information, the social sharing of which would have been adaptive for specific reasons.

To assume special adaptations for verbal communication, naturally, is also to assume adaptations that depend on, or co-emerge with, language, and this leads me to my last hypothesis. If Dunbar's statistics are right and the exchange of social information is in fact that predominant in our verbal behavior, then he might also be right in assuming that the exchange of social knowledge ("gossip") was the first crucial motor in developing and elaborating human language to the complex semiotic system that we know today. And then the other narration instincts I have outlined here might be kind of epiphenomena in that process, which started as incidental uses of this newly emerging semiotic system but then were genetically stabilized as distinct adaptations because of the high efficiency with which language also served to reply to a number of other specific selection pressures (like coordinating collective preparations of shelter, finding new food resources, enhancing the survival fitness of the offspring, spreading new information).

My list of one primary and four secondary narration instincts certainly is neither exhaustive nor infallible. Some of these instincts may be sorted out (or at least reformulated) by future research and different ones might be added. My aim in beginning such a list was not so much to provide another essay on the subject of "Storytelling as Adaptation" but rather to exemplify what we are really talking about if we want to consider storytelling to be a biological adaptation: we are talking about hard-wired instincts of the human animal! It seems important to me to carefully distinguish such biologically shaped features of the human mind from the manifold cultural uses of language and narration, if evolutionary explanations shall seriously contribute to literary theory.

\section{Conclusion}

Since the narrative "format" is sufficiently explained by the basic working principles of the human brain and their combinations with various cognitive abilities (such as mental scripts and linguistic skills), I would not agree with the opinion "that narrative appears to meet the criteria of special design" (Scalise Sugiyama 2005, p. 191), if this is to assume a distinctly evolved cognitive program specifically designed to produce such forms of speech. However, I proposed that our commonsensical (albeit vague and shifting) gestalt notion of "story" could be the blended result of a number of adaptations that prompt us to talk (proto-narrate) about specific topics in specific situations. In that way, the proto-typicality of third-person narration may be due to the 
importance of reporting social occurrences to those group members who have not witnessed them themselves but whose ability to act within their social world, too, depends on having as comprehensive and elaborate a mental model of this social world as possible. Second, the intuition that a "good story" should involve something unusual or problematic could derive from the selection pressures that shaped the presumed innate topics: weather conditions that demand collective efforts of shelter; potentially life-threatening dangers, like predators; short-term available food resources; social conflicts; novelty and strangeness. Third, the odd fact that "untrue" stories are at least as prototypical as "true" stories might arise from the functional equivalence of actual social occurrences with encrypted, ${ }^{24}$ generalized, hypothetical, parabolic, etc., renderings of social issues; from fashioning "super-normal" fear stimuli to accelerate the ontogenetic development of especially survival-enhancing mechanisms; as well as from the often speculative quality of explaining the unknown.

However, since our intuitive notion of stories could also result from certain cultural uses of narration, the fact that we have such a notion is not sufficient evidence that storytelling is a biological adaptation. Therefore, I have suggested the examination of the proximate mechanism ${ }^{25}$ as a more appropriate method of proving (or refuting) this hypothesis. As a first approach, I have outlined several possible "narration instincts" which, by their "instinctive" nature, should be distinguishable from other, "merely cultural" narrative activities.

Seen in this light, Scalise Sugiyama's proposition "that narrative is an information storage and transmission system" (Scalise Sugiyama 2005, p. 190) which emerged with our occupation of the "cognitive niche" 26 still holds valid but also seems a slightly over-generalized formula, because it does not explicitly differentiate between such instinctively biased narrations on the one hand and narration as a flexible cultural activity on the other. Our species' adaptation to the "cognitive niche" is the beginning of an immensely increased flexibility of human cognition and behavior (including language ${ }^{27}$ ) and, at the same time, of an increasing dependence on "culture." And culture (in the sense of a mental "interface" or "in-between world" that mediates between our evolved nervous system and the environment (cf. Eibl

24 Because of a need for "indirection" in small-scale societies, e.g.; cf. Heeschen 2001a and 2001b.

25 Cf. the five core components of any adaptationist analysis as listed by Tooby and Cosmides 1992, pp. $73 \mathrm{f}$.

26 This useful metaphor for the particular "ecological niche" to which the human species is specifically adapted and which explains that species' most significant traits was coined by Tooby and DeVore 1987.

27 Cf. Pinker 2003 on language as an adaptation to the "cognitive niche." 
2009) surely is, to a large extent, ${ }^{28}$ organized by "narratives." Thus, to say that narrative is an adaptation (note that Scalise Sugiyama remains cautious here) would not be more wrong or right than saying that culture is an adaptation, but it would also be as little informative as the latter unless we begin to specify particular behavioral programs. And finally, if the assumption that narrative is an adaptation shall be more than the assumption that language is an adaptation, then we should also be able to demonstrate how those behavioral programs have specifically shaped the proto-typical form of utterance called narrative.

As things stand, I think that most of what we call narratives is classified best as cultural exploitations of preexistent traits of the human mind. Even stories on topics of obvious cross-cultural prevalence and evident biological significance (like, for instance, the topic of love and reproduction) should be seen as byproducts of a number of biological substrates as long as we cannot, first, indicate the fitness-enhancing value of socially communicating those kinds of information and, second, verify the cross-culturally reliable performance of the proximate mechanism. In this chapter, I have hypothesized a number of "narration instincts" for which I consider it possible to gain such evidence. The question whether I am right, however, cannot be answered theoretically but only empirically. To decide whether we really have such instincts as I have inferred from a rather intuitive observation of human behavior, needs well-directed testing for each of them individually. But I think my theoretical considerations can help to develop suitable experimental designs by specifying our questions. For instance: Do people really produce significantly more stories about how they bought a lawn mower for only half the price than about mowing the lawn the same afternoon? If not, the hypothesis of a "food call narration instinct" as stated here fails. Do people really include scary motifs on a larger scale than other motifs in stories they tell children? Or: Do people, more often than not, conversationally exchange newly acquired knowledge (like for instance newspaper science news) without particular relevance to their occupation or being personally interested in the topic? - Those questions may sound bizarre to literary scholars, but they are not at all absurd if taken in the sense of risky hypotheses to test our theory.

28 Notably, not all cultural narratives are prototypical "stories" in the sense introduced here. As Heeschen 2001b observes, for example, myths often tend to an "enumerative structure dispensing with the logics of event structure" (p. 154) and thus exploit the full potential of the "objectifying" (cf. Eibl 2004, pp. 213-275) quality of human language. Cf. also Mellmann $2010 \mathrm{a}$ on the large continuum between strongly experiential formats on the one hand and what could be called "textbook" versions of narration on the other. 


\section{References}

Abbott, H. Porter, "The Evolutionary Origins of the Storied Mind. Modeling the Prehistory of Narrative Consciousness and Its Discontents," in: Narrative 8.3 (2000), pp. 247-256.

Bamberg, Michael G. W. (ed.), Oral Versions of Personal Experience: Three Decades of Narrative Analysis, Hillsdale, NJ: Erlbaum, 1997 (= Journal of Narrative and Life History 7.1-4).

Barrett, Louise / Robin Dunbar / John Lycett, Human Evolutionary Psychology, London: Palgrave Macmillan, 2001.

Bischof, Norbert, Das Krafteld der Mythen: Signale aus der Zeit, in der wir die Welt erschaffen haben, Munich: Piper, 1998.

Booker, Christopher, The Seven Basic Plots: Why We Tell Stories, London, New York: Continuum, 2004.

Boyd, Brian, On the Origins of Stories: Evolution, Cognition, and Fiction, Cambridge, London: Belknap, 2009.

Bruner, Jerome, "The Narrative Construction of Reality," in: Critical Inquiry 18.1 (1991/ 92), pp. 1-21.

Burkert, Walter, Kulte des Altertums: Biologische Grundlagen der Religion, Munich: C. H. Beck, 1998.

Carrithers, Michael, "Narrativity. Mindreading and Making Societies," in: Natural Theories of Mind: Evolution, Development and Simulation of Everyday Mindreading, ed. by Andrew Whiten, Oxford: Blackwell, 1991, pp. 305-317.

Chapman, Colin A. / Louis Lefebvre, "Manipulating Foraging Group Size: Spider Monkey Food Calls at Fruiting Trees," in: Animal Behaviour 39 (1990), pp. 891-896.

Cosmides, Leda / John Tooby, "Consider the Source: The Evolution of Adaptations for Decoupling and Metarepresentation," in: Metarepresentations: A Multidisciplinary Perspective, ed. by Dan Sperber, Oxford: Oxford UP, 2000, pp. 53-115.

Damasio, Antonio R., The Feeling of What Happens: Body and Emotion in the Making of Consciousness, New York: Harcourt Brace, 1999.

Dautenhahn, Kerstin, "Stories of Lemurs and Robots: The Social Origin of Story-Telling," in: Narrative Intelligence, ed. by Michael Mateas and Phoebe Sengers, Amsterdam, Philadelphia: John Benjamins, 2003, pp. 63-90.

Donald, Merlin, Origins of the Modern Mind: Three Stages in the Evolution of Culture and Cognition, Cambridge, MA, London: Harvard UP, 1991.

Dunbar, Robin, "Gossip in Evolutionary Perspective," Review of General Psychology 8.2 (2004), pp. 100-110.

Dunbar, Robin / N. D. C. Duncan / Anna Marriott, "Human Conversational Behaviour," in: Human Nature 8.3 (1997), pp. 231-246.

Eibl, Karl, Animal poeta: Bausteine der biologischen Kultur- und Literaturtheorie, Paderborn: Mentis, 2004.

-, "Epische Triaden," in: Journal of Literary Theory 2.2 (2008), pp. 197-208.

-, Kultur als Zwischenwelt: Eine evolutionsbiologische Perspektive, Frankfurt/M.: Suhrkamp, 2009.

-, "Sprache macht Kultur," in: Evolution und das heutige Bild vom Menschen, ed. by Jochen Oehler, Heidelberg: Springer, 2010, pp. 109-126. 
Evans, Christopher S. / Linda Evans, "Chicken Food Calls Are Functionally Referential," in: Animal Behaviour 58 (1999), pp. 307-319.

Flesch, William, Comeuppance: Costly Signaling, Altruistic Punishment, and Other Biological Components of Fiction, Cambridge, MA, London: Harvard UP, 2007.

Foster, Eric K., "Research on Gossip: Taxonomy, Methods, and Future Directions," in: Review of General Psychology 8.2 (2004), pp. 78-99.

Hauser, Marc D. / W. Tecumseh Fitch, "What are the Uniquely Human Components of the Language Faculty?" in: Language Evolution: States of the Art, ed. by Morten H. Christiansen and Simon Kirby, New York: Oxford UP, 2003, pp. 158-181.

Heeschen, Volker, “The Narration 'Instinct': Signalling Behaviour, Communication, and the Selective Value of Storytelling," in: New Essays on the Origin of Language, ed. by Jürgen Trabant and Sean Ward, Berlin, New York: de Gruyter, 2001, pp. 179-196 $(=2001 \mathrm{a})$.

-, "The Narration 'Instinct': Everyday Talk and Aesthetic Forms of Communication (in Communities of the New Guinea Mountains)," in: Verbal Art Across Cultures: The Aesthetics and Proto-Aesthetics of Communication, ed. by Hubert Knoblauch and Helga Kotthoff, Tübingen: Narr, 2001, pp. 137-165 (= 2001b).

Herman, David, Story Logic: Problems and Possibilities of Narrative, Lincoln, London: University of Nebraska Press, 2002.

Hoeg, Jerry, "Why Did Narrative Evolve? (Human) Nature and Narrative," in: Studies in the Literary Imagination 42.2 (2009), pp.1-13.

Hogan, Patrick, The Mind and Its Stories: Narrative Universals and Human Evolution, Cambridge, New York: Cambridge UP, 2003.

Kafalenos, Emma, Narrative Causalities, Columbus: Ohio State UP, 2006.

Keen, Suzanne, Empathy and the Novel, Oxford: Oxford UP, 2007.

László, János, "Epidemiology of Representations, Social Representations and Narratives," in: Journal of Cultural and Evolutionary Psychology 1.3\&4 (2003), pp. 191-204.

Lloyd, Dan Edward, Simple Minds, Cambridge, MA: MIT Press, 1989.

Mar, Raymond A. / Keith Oatley / Jacob Hirsh / Jennifer dela Paz / Jordan B. Peterson, "Bookworms versus Nerds: Exposure to Fiction versus Non-fiction, Divergent Associations with Social Ability, and the Simulation of Fictional Social Worlds," in: Journal of Research in Personality 40.5 (2006), pp. 694-712.

Mar, Raymond A. / Jennifer L. Tackett / Chris Moore, "Exposure to Media and Theory-of-mind Development in Preschoolers," in: Cognitive Development 25.1 (2009), pp. 69-78.

Mellmann, Katja, "Voice and Perception: An Evolutionary Approach to the Basic Functions of Narrative," in: Toward a Cognitive Theory of Narrative Acts, ed. by Frederick Luis Aldama, Austin: University of Texas Press, 2010, pp. 119-140 (= 2010a).

-, "The Multifunctionality of Idle Afternoons: Art and Fiction in Boyd's Vision of Evolution," in: JLTonline, 9 March 2010: http://www.jltonline.de/index.php/reviews/article/view/170/528 (=2010b).

Mesoudi, Alex / Andrew Whiten / Robin Dunbar, "A Bias for Social Information in Human Cultural Transmission," in: British Journal of Psychology 97.3 (2006), pp. 405423. 
Oatley, Keith / Raymond A. Mar, "Evolutionary Pre-adaptation and the Idea of Character in Fiction," in: Journal of Cultural and Evolutionary Psychology 3.2 (2005), pp. 179_ 194.

Pinker, Steven, "Language as an Adaptation to the Cognitive Niche," in: Language Evolution: States of the Art, ed. by Morten H. Christiansen and Simon Kirby, New York: Oxford UP, 2003, pp. 16-37.

Scalise Sugiyama, Michelle, "On the Origins of Narrative: Storyteller Bias as a FitnessEnhancing Strategy," in: Human Nature 7.4 (1996), pp. 403-425.

-, "Narrative Theory and Function: Why Evolution Matters," in: Philosophy and Literature 25.2 (2001), pp. 233-250 (= 2001a).

-, "Food, Foragers, and Folklore: The Role of Narrative in Human Subsistence," in: Evolution and Human Behavior 22.4 (2001), pp. 221-240 (= 2001b).

-, "Predation, Narration, and Adaptation: Little Red Riding Hood Revisited," in: Interdisciplinary Literary Studies 5.2 (2004), pp. 108-127.

-, "Reverse-Engineering Narrative: Evidence of Special Design," in: The Literary Animal: Evolution and the Nature of Narrative, ed. by Jonathan Gottschall and David Sloan Wilson, Evanston, IL: Northwestern UP, 2005, pp. 177-196.

-, "Lions and Tigers and Bears: Predators as a Folklore Universal," in: Heuristiken der Literaturwissenschaft: Disziplinexterne Perspektiven auf Literatur, ed. by Uta Klein, Katja Mellmann and Steffanie Metzger, Paderborn: Mentis, 2006, pp. 319-331.

-, "Narrative as Social Mapping. Case Study: The Trickster Genre and the Free Rider Problem," in: Ometeca 12 (2008), pp. 24-42.

Scalise Sugiyama, Michelle / Lawrence Sugiyama, "A Frugal (Re)Past: Use of Oral Tradition to Buffer Foraging Risk," in: Studies in the Literary Imagination 42.3 (2009), pp. $15-41$.

Schwender, Clemens, Medien und Emotionen: Evolutionspsychologische Bausteine einer Medientheorie, Wiesbaden: Deutscher Universitäts-Verlag, ${ }^{2} 2006$.

Tomasello, Michael, The Cultural Origins of Human Cognition, Cambridge, MA, London: Harvard UP, 1999.

Tooby, John / Irven DeVore, "The Reconstruction of Hominid Behavioral Evolution through Strategic Modeling," in: The Evolution of Human Behavior: Primate Models, ed. by Warren G. Kinzey, Albany: State University of New York Press, 1987, pp. 183237.

Tooby, John / Leda Cosmides, “The Psychological Foundations of Culture," in: The Adapted Mind. Evolutionary Psychology and the Generation of Culture, ed. by Jerome H. Barkow, L. Cosmides and J. Tooby, New York, Oxford: Oxford UP, 1992, pp. 19-136.

-, "Does Beauty Build Adapted Minds? Toward an Evolutionary Theory of Aesthetics, Fiction and the Arts," in: SubStance: A Review of Theory and Literary Criticism 30.1\&2 (2001), pp. 6-27.

Tsiknaki, Eirini, Literatur und Persönlichkeitsentwicklung: Eine empirische Untersuchung zur Erfassung des Zusammenhangs zwischen literarischem Lesen und Emotionaler Intelligenz, Munich: Meidenbauer, 2005. 